\title{
Probabilistic flood hydrographs using Monte Carlo simulation: potential impact to flood inundation mapping
}

\author{
$\underline{\text { M. Loveridge }}^{\text {a }}$, A. Rahman ${ }^{a}$ and M. Babister ${ }^{\text {b }}$ \\ ${ }^{a}$ School of Computing, Engineering \& Mathematics, University of Western Sydney, New South Wales \\ Email: mel.taylor@uws.edu.au \\ ${ }^{b}$ WMAwater, Sydney, New South Wales
}

\begin{abstract}
Flood inundation modelling generally involves two steps. The first involves the use of a hydrologic model, such as RORB, to estimate the design flood hydrograph for a given design storm event. These models require several inputs, such as design rainfalls (i.e. duration, intensity \& temporal pattern), losses, baseflow and routing parameters; each of which has an associated degree of uncertainty that can affect the shape and magnitude of the estimated design flood hydrograph. The second involves the use of these design flood hydrographs as inputs into a hydraulic model, to estimate the flood inundation extent. Given the uncertainties in hydrologic modelling and their importance in mapping inundation extents, it is of interest to determine the potential impacts of hydrological uncertainties on flood inundation mapping. This paper, therefore, considers how the uncertainties in design losses can affect the hydraulic analysis.
\end{abstract}

The Orara River catchment in north-east NSW was selected for this study, which covers an area of $135 \mathrm{~km}^{2}$. The data during the period of 1970 to 2009 was used, with both streamflow (204025) and a pluviograph station (59026) available throughout this period. For 43 storm events, rainfall spatial patterns are produced using ordinary kriging, with 23 daily rainfall stations, and baseflow was separated using a recursive digital filter. The RORB rainfall-runoff model was adopted, with the non-linearity exponent fixed at 0.8 and the routing parameter fixed at 15 .

Both the initial and continuing losses were calibrated for each event and then examined to find the best fit probability distribution. From the 27 parametric distributions, it was found that the initial loss (IL) can be approximated by the 2-parameter Gamma distribution and the continuing loss (CL) can be approximated by the 3-parameter Weibull distribution. A Monte Carlo framework was adopted to quantify uncertainties in the losses. Ten thousand randomly generated initial and continuing loss values were run through RORB in order to derive confidence limits for the peak flow, flood volume and time to peak flow characteristics. These derived flood frequency curves (DFFC) are then compared to observed floods and an at-site flood frequency analysis (FFA).

The median relative errors of the DFFC when compared to the at-site FFA were found to be $13.5 \%$ and $23.1 \%$, for the peak flow and flood volumes, respectively. The flood volumes were found to be more consistent across all probabilities with a range of $-3.6 \%$ to $-26.6 \%$, as compared to the peak flows that ranged from $9 \%$ to $39.5 \%$. The confidence band (referring to the $5^{\text {th }}$ and $95^{\text {th }}$ percentiles) were found to be smallest about the time to peak flow, which only varied up to $10 \%$, followed by the peak flows which showed around $\pm 55 \%$ variability. The flood volumes saw the widest confidence bands, with a median variation of about $\pm 63 \%$, which increased to a maximum of about $\pm 105 \%$.

It has been found that the Monte Carlo framework adopted in this study has the ability to produce more accurate and realistic design flood estimates, however, these improvements have not yet been carried through to the hydraulic model. Flood inundation maps are generally still depicted as a single deterministic flood inundation prediction for a given deterministic design hydrograph. As found in a study by Merwade et al. (2008) when the standard errors in peak flows ranged from $-36.1 \%$ to $56.5 \%$, this caused a shift in the water surface elevation from $-0.4 \mathrm{~m}$ to $1 \mathrm{~m}$ and the extent of floodplain inundation varied in width from $54.3 \mathrm{~m}$ to $90.2 \mathrm{~m}$. With peak flows ranging up to $\pm 55 \%$ in this study, potentially causing these types of errors in the inundation extents, it is clear that probability-weighted flood inundation extents need to be modelled rather than a single deterministic prediction.

Keywords: $\quad$ Monte Carlo simulation, rainfall losses, probability distribution, flood risk 


\section{INTRODUCTION}

Design flood estimates are often required for flood risk management, for example in the design of bridges, culverts, dams and levees, and floodplain mapping. This is expressed as a flood characteristic (usually taken as the peak flow or flood volume) associated with a specific annual exceedance probability (AEP). The majority of rainfall-based flood estimates in Australia are based on the design event approach (DEA), which attempts to transform a design rainfall of a given AEP into a design flood of the same AEP. The main assumption of the DEA is that each input variable can be expressed by a measure of central tendency, except for rainfall depth.

All inputs for rainfall-runoff modelling have an associated degree of uncertainty that can affect the shape and magnitude of the estimated design flood hydrograph. Therefore, an alternative method is required which is able to account for these uncertainties. Monte Carlo simulation, based on the joint probability approach, is able to explicitly allow for the probabilistic nature of key inputs and their correlation to determine probability-distributed outputs (Rahman et al. 2002a). Of the key inputs, losses have been consistently identified as one of the key downfalls in Australian flood hydrology. A number of studies have been devoted to rainfall losses, including those by Hill et al. (2013), Loveridge \& Rahman (2012), Ilahee \& Imteaz (2009), Siriwardena et al. (1997), Mein et al. (1995), Nandakumar et al. (1994), Walsh (1991) and Waugh (1990).

Hydrologic modelling uncertainty propagates through to the flood inundation predictions and whilst many studies have investigated hydrologic uncertainties (Loveridge et al. 2013, Tularam \& Ilahee 2007, Ishak \& Rahman 2006, Rahman et al. 2002b), the effect of hydrologic uncertainties on hydraulic models is largely unknown. This is primarily due to the intense computing power required to simulate flood flow behaviour across a floodplain for many realisations of the hydrologic process (as in Monte Carlo simulation). Given the uncertainty in hydrologic models and its importance in flood inundation mapping, this paper considers how uncertainties in losses can affect the hydraulic analysis. The uncertainties in the initial and continuing losses are quantified by adopting a limited Monte Carlo framework with 10,000 randomly generated loss values.

\section{STUDY AREA AND DATA}

For this study, the Orara River catchment was selected, which is located approximately $10 \mathrm{~km}$ west of Coffs Harbour in NSW. The catchment was selected based on the daily rainfall gauge density and availability of long periods of quality pluviograph and streamflow records. The Orara River catchment, as shown in Figure 1 , covers an area of $135 \mathrm{~km}^{2}$, with a catchment relief of 795 meters. The catchment is principally influenced by summer rainfall, with a mean annual rainfall of $1,793 \mathrm{~mm}$.

There are a total 37 years of streamflow data recorded for the Orara River at Karangi (204025). A pluviograph station (59026) located near the catchment centroid provided hourly rainfall data; whilst an additional 23 daily rainfall gauges provided greater spatial detail across the catchment. The data period from 1970-2009 (39 years) was used in this study, which was available for both the pluviograph and streamflow gauges.
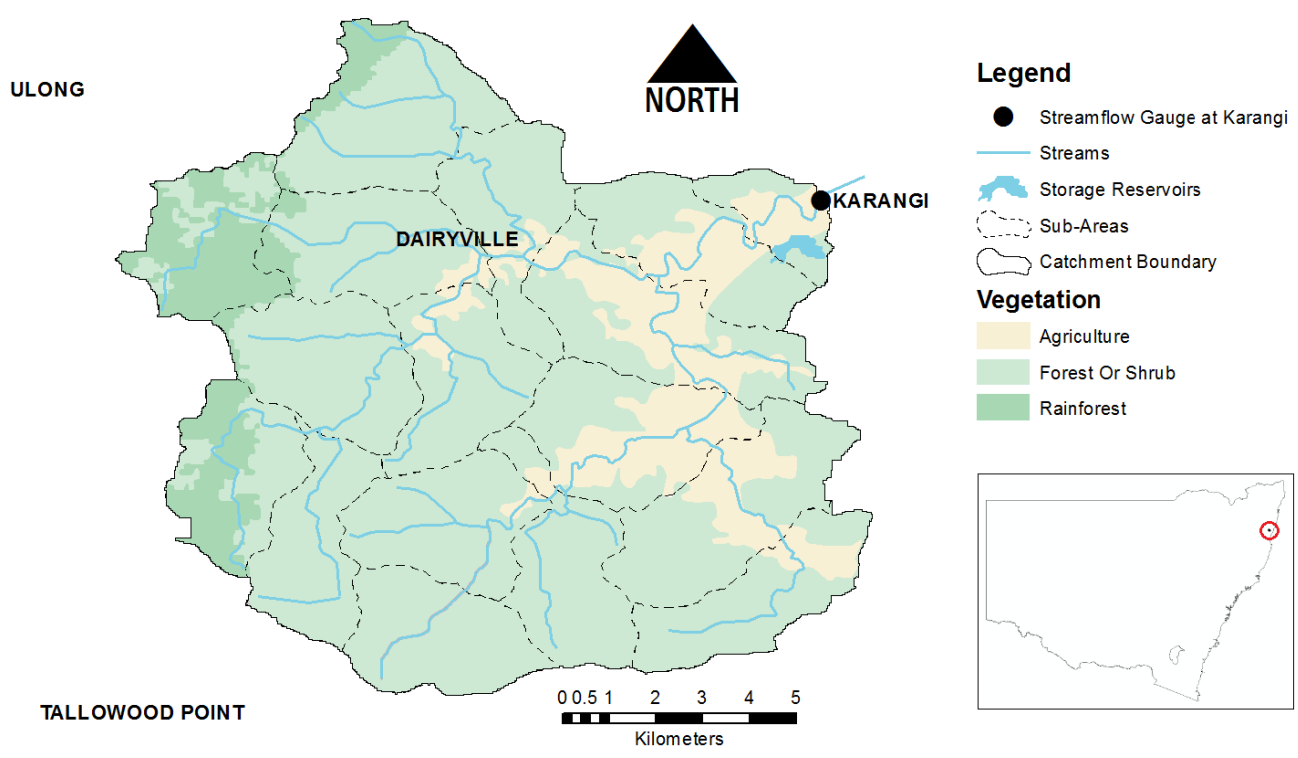

Figure 1: Catchment location and detailed map (inset shows location within NSW). 


\section{METHODOLOGY}

Storm events were selected based on rainfall bursts of 12 hour duration, resulting in a total of 43 events for the study catchment. The rainfall spatial pattern for each event was produced using ordinary kriging, with daily rainfall stations in and around the study catchment. The contribution of baseflow to each event was removed using a recursive digital filter with 9 passes and a filter factor of 0.925 (see Murphy et al., 2011). The catchment modelling for the study area was performed using the RORB rainfall-runoff model, with the non-linearity exponent $(\mathrm{m})$ being fixed at 0.8 (Laurenson et al., 2007).

The initial loss-continuing loss (IL-CL) model was adopted, as it has been widely used across Australia. The IL, CL and routing parameter $\left(\mathrm{k}_{\mathrm{c}}\right)$ were calibrated for each event using RORB, by manually fitting the modelled hydrograph to the surface runoff. The median $\mathrm{k}_{\mathrm{c}}$ value, calibrated for the Orara River catchment, was found to be 15 and was kept fixed in the analysis. The loss data was tested against 27 parametric distributions, including bounded, unbounded, non-negative and advanced distributions, to find the best fit distribution for each loss parameter.

Monte Carlo simulation is commonly adopted for uncertainty analyses in modelling. It requires the random generation of many realisations of the inputs (in this case 10,000 values for the initial and continuing losses) that are run through the RORB model in order to derive confidence limits for a given flood characteristic. For instance, in this paper, the peak flow, flood volume and time to peak flow were stored and then used to derive the flood frequency curve for that characteristic. Figure 2 illustrates the Monte Carlo framework adopted in this study. An at-site flood frequency analysis (FFA) was also performed as an independent comparison, by adopting the LP3 distribution in a Bayesian framework using FLIKE (Kuczera, 1999).

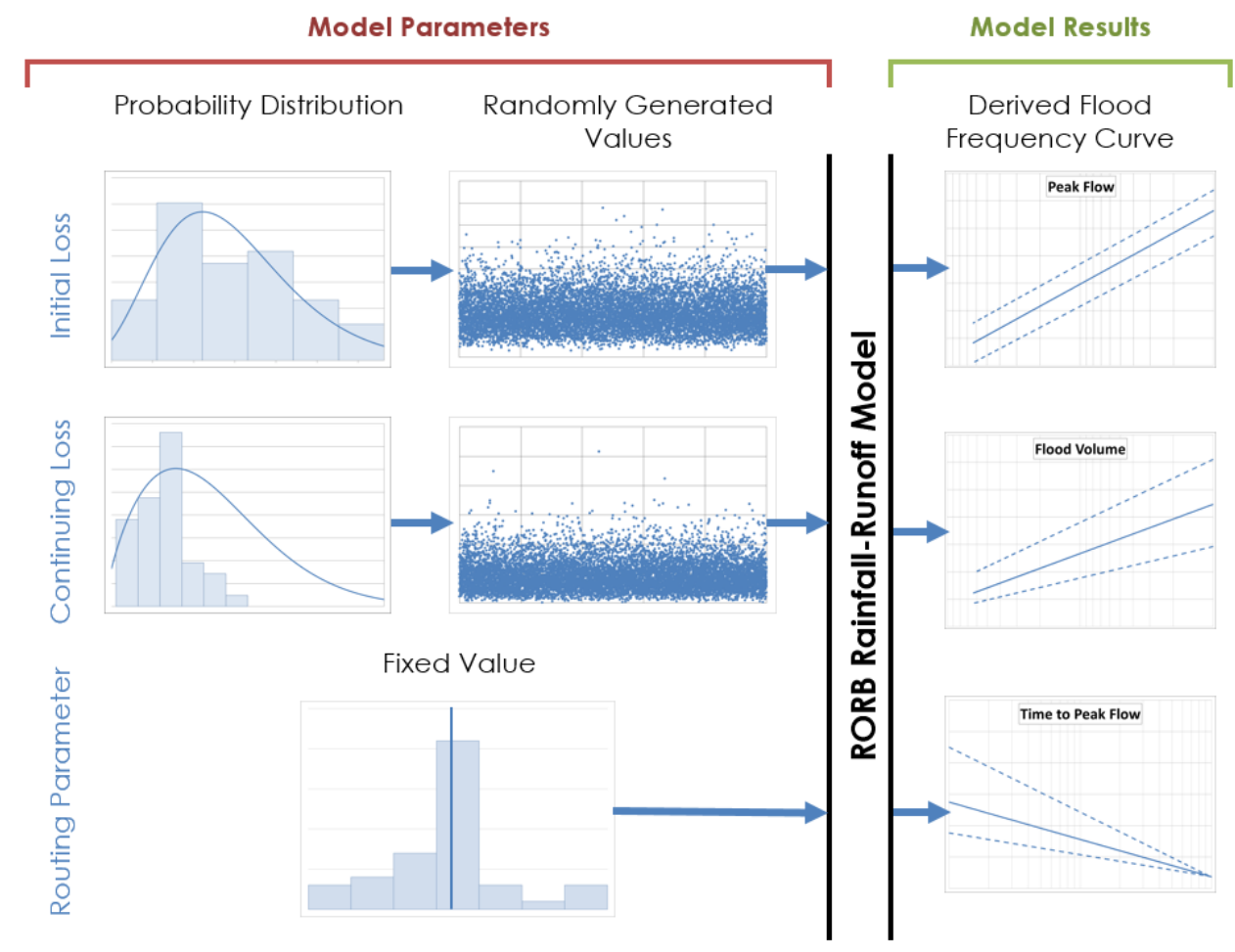

Figure 2: Conceptual diagram of the limited Monte Carlo framework (with stochastic losses \& other inputs fixed).

\section{RESULTS AND DISCUSSION}

The variability in the calibrated losses were investigated; from the 27 parametric distributions tested it was found that the initial loss (IL) can be approximated by the 2-parameter Gamma distribution and the continuing loss (CL) can be approximated by the 3-parameter Weibull distribution (refer to Loveridge et al, 2013). The two losses were treated independently of each other, as it was found that there was little correlation between the IL and CL. 


\subsection{Variability in peak flows}

The loss values derived from the aforementioned distributions were combined with other design inputs to derive the design peak flows, which were compared to the observed flood peaks and the at-site flood frequency analysis (see Figure 3). The 5\% and 95\% confidence limits are shown as the blue dashed lines in Figure 3. From this plot, it can be seen that the derived flood frequency curve (DFFC) reproduces the shape of the at-site FFA reasonably well, however it has a tendency to overestimate peak flows. In terms of percentages, the median relative error across all AEP's was found to be $13.5 \%$, ranging from 9 to $39.5 \%$ (Table 1). A relative error of $0 \%$ is ideal, however this is never possible in hydrology. More specifically, in regional flood frequency analysis relative errors of up to $40 \%$ to $60 \%$ are reasonable (see Haddad and Rahman, 2012).

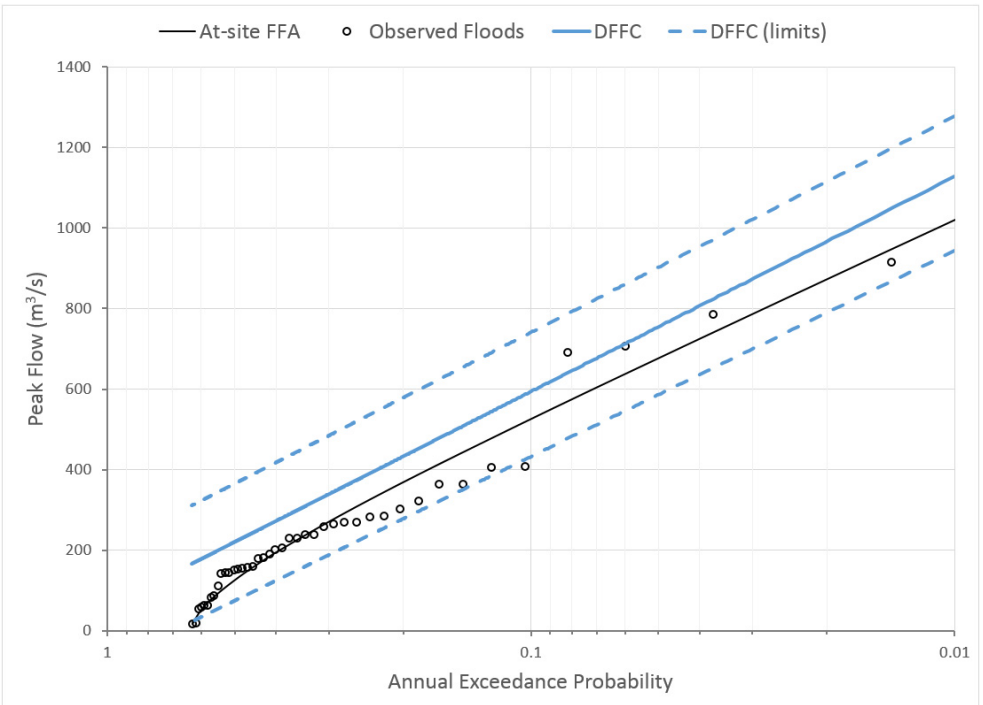

Figure 3: $\quad$ Derived flood frequency curve (DFFC) for peak flows

The peak flows have a median variability (referring to the $5 \%$ and $95 \%$ confidence limits) of around $\pm 25 \%$. It can be seen that there is a much higher variability for more frequent AEP's, with about $\pm 55 \%$ and $\pm 34 \%$ variation for AEP's of 0.39 and 0.18 , respectively. This reduces for the less frequent AEP's to around $\pm 18 \%$ and $\pm 15 \%$ for AEP's of 0.02 and 0.01 , respectively.

Table 1:Relative error of the peak flows derived from the Monte Carlo simulation and the at-site flood frequency analysis

\begin{tabular}{|l|c|c|c|c|c|c|}
\hline \multirow{2}{*}{ Peak Flow $\left(\mathbf{m}^{\mathbf{3}} / \mathbf{s}\right)$} & \multicolumn{7}{|c|}{ Annual Exceedance Probability } \\
\cline { 2 - 7 } & $\mathbf{0 . 3 9}$ & $\mathbf{0 . 1 8}$ & $\mathbf{0 . 1 0}$ & $\mathbf{0 . 0 5}$ & $\mathbf{0 . 0 2}$ & $\mathbf{0 . 0 1}$ \\
\hline DFFC & 276 & 479 & 608 & 776 & 954 & 1122 \\
\hline FFA & 199 & 392 & 536 & 682 & 875 & 1021 \\
\hline Relative Error & $39.5 \%$ & $22.3 \%$ & $13.3 \%$ & $13.7 \%$ & $9.0 \%$ & $9.9 \%$ \\
\hline
\end{tabular}

\subsection{Variability in flood volumes}

The DFFC for the flood volumes were compared to the observed flood peaks and the at-site flood frequency analysis (see Figure 4). The 5\% and 95\% confidence limits are shown as the blue dashed lines in Figure 4. From the DFFC it can be seen that, unlike the peak flows, the flood volumes were consistently underestimated. The relative errors were fairly consistent for most AEP's (see Table 2), with a median relative error across all AEP's of $-23.1 \%$ and ranging from $-13.6 \%$ to $-26.6 \%$.

The flood volumes have a median variability of around $\pm 63 \%$. Compared with the peak flows, the flood volumes have significantly more variability across all probabilities. There is a higher variability for more frequent AEP's, with about $\pm 105 \%$ and $\pm 78 \%$ variation for AEP's of 0.39 and 0.18 , respectively. This reduces for the less frequent AEP's to around $\pm 50 \%$ and $\pm 43 \%$ for AEP's of 0.02 and 0.01 , respectively. It is worth noting that whilst the variability of peak flows was fairly evenly distributed, the flood volumes have a much wider band for the upper limit than for the lower limit, particularly for more frequent AEP's. 
Loveridge et al., Probabilistic flood hydrographs using Monte Carlo simulation and their effect on flood risk

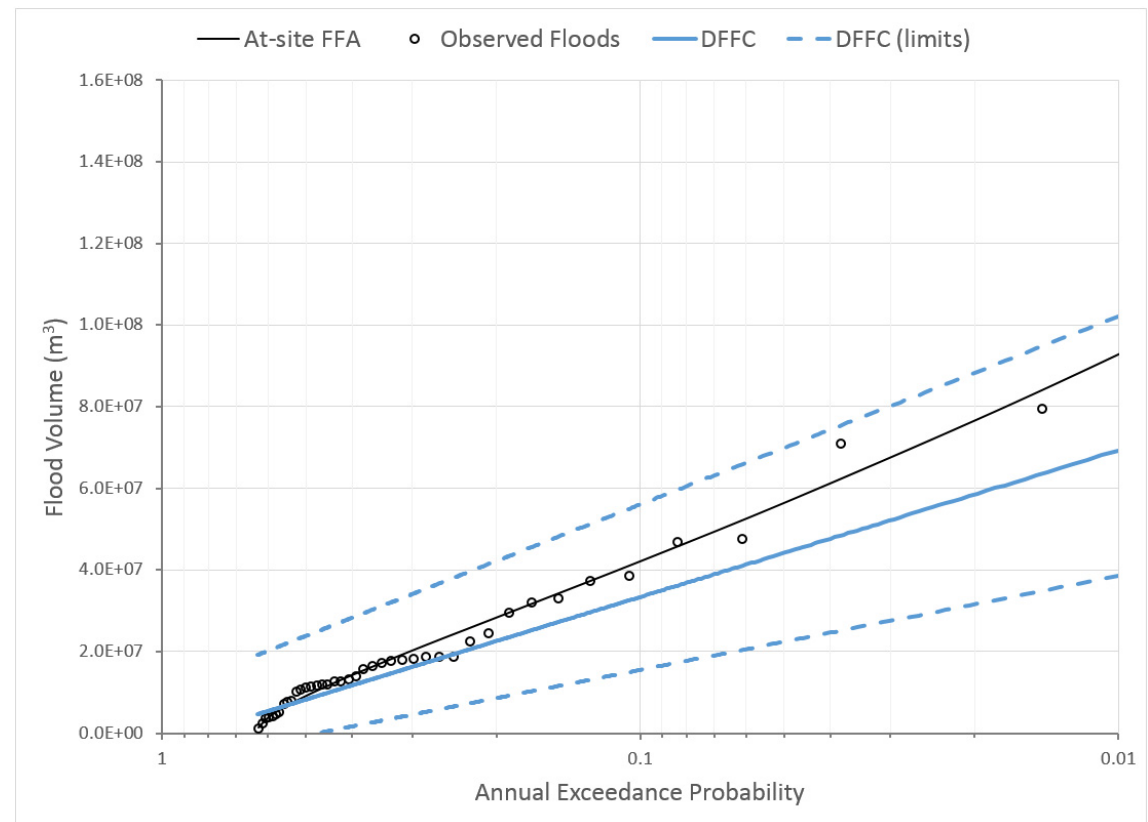

Figure 4: Derived flood frequency curve (DFFC) for flood volumes

Table 2: Relative error of the flood volumes derived from the Monte Carlo simulation and the at-site flood frequency analysis

\begin{tabular}{|l|c|c|c|c|c|c|}
\hline \multirow{2}{*}{ Flood Volume $\mathbf{( m}^{\mathbf{3}}$ ) } & \multicolumn{7}{|c|}{ Annual Exceedance Probability } \\
\cline { 2 - 7 } & $\mathbf{0 . 3 9}$ & $\mathbf{0 . 1 8}$ & $\mathbf{0 . 1 0}$ & $\mathbf{0 . 0 5}$ & $\mathbf{0 . 0 2}$ & $\mathbf{0 . 0 1}$ \\
\hline DFFC & $1.25 \mathrm{E}+07$ & $2.37 \mathrm{E}+07$ & $3.16 \mathrm{E}+07$ & $4.22 \mathrm{E}+07$ & $5.90 \mathrm{E}+07$ & $7.15 \mathrm{E}+07$ \\
\hline FFA & $1.45 \mathrm{E}+07$ & $3.02 \mathrm{E}+07$ & $4.30 \mathrm{E}+07$ & $5.69 \mathrm{E}+07$ & $7.67 \mathrm{E}+07$ & $9.29 \mathrm{E}+07$ \\
\hline Relative Error & $-13.6 \%$ & $-21.6 \%$ & $-26.6 \%$ & $-25.8 \%$ & $-23.1 \%$ & $-23.0 \%$ \\
\hline
\end{tabular}

\subsection{Variability in time to peak flows}

The DFFC for the time to peak flows, including the $5 \%$ and $95 \%$ confidence limits (shown as the blue dashed lines), are shown in Figure 5 . The time to peak has a median variability of around $\pm 4 \%$, significantly less than both the peak flow and flood volume. There is more variability for more frequent AEP's, with about $\pm 9 \%$ and $\pm 7 \%$ variation for AEP's of 0.39 and 0.18 , respectively. Again, this variability reduces for less frequent AEP's, to around $\pm 2.3 \%$ for both AEP's of 0.02 and 0.01 . Similar to the flood volumes, the time to peak has a wider band for the upper limit than for the lower limit.

\subsection{Variability in hydrograph shapes}

Out of the 10,000 hydrographs generated for each duration and probability, a sample of 240 were randomly selected and plotted, as seen in Figure 6. The hydrographs for the 12 hour duration were plotted (as this is the critical duration for the Orara River catchment) and for AEP's ranging from 0.39 to 0.01 . From these plots, it is clear that there is significant variation between the design hydrographs produced when uncertainties in the design losses are considered. The variability between each individual hydrograph can also be seen to diminish as the AEP frequency decreases.

\subsection{Impact on flood inundation maps}

Flood inundation modelling involves two processes; firstly, a hydrologic model, such as RORB, is used to estimate the design flood hydrograph for a given storm event, and; secondly, a hydraulic model is used to estimate the flood inundation extent. In Australian practice the resulting flood inundation maps are depicted by a single deterministic prediction for the flood extent for the given hydrograph, whether it be for a 0.01 or 0.5 AEP. However, flood extents are not adequately portrayed by a single deterministic line due to the inherent uncertainties in design floods, model parameters, topography and model structure. 


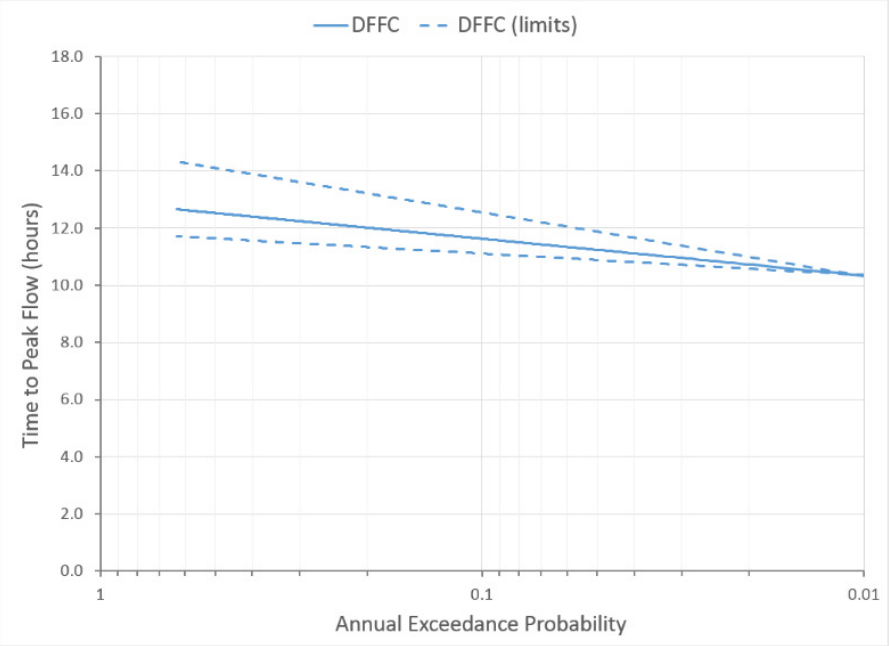

Figure 5: $\quad$ Derived flood frequency curve (DFFC) for time to peak flow
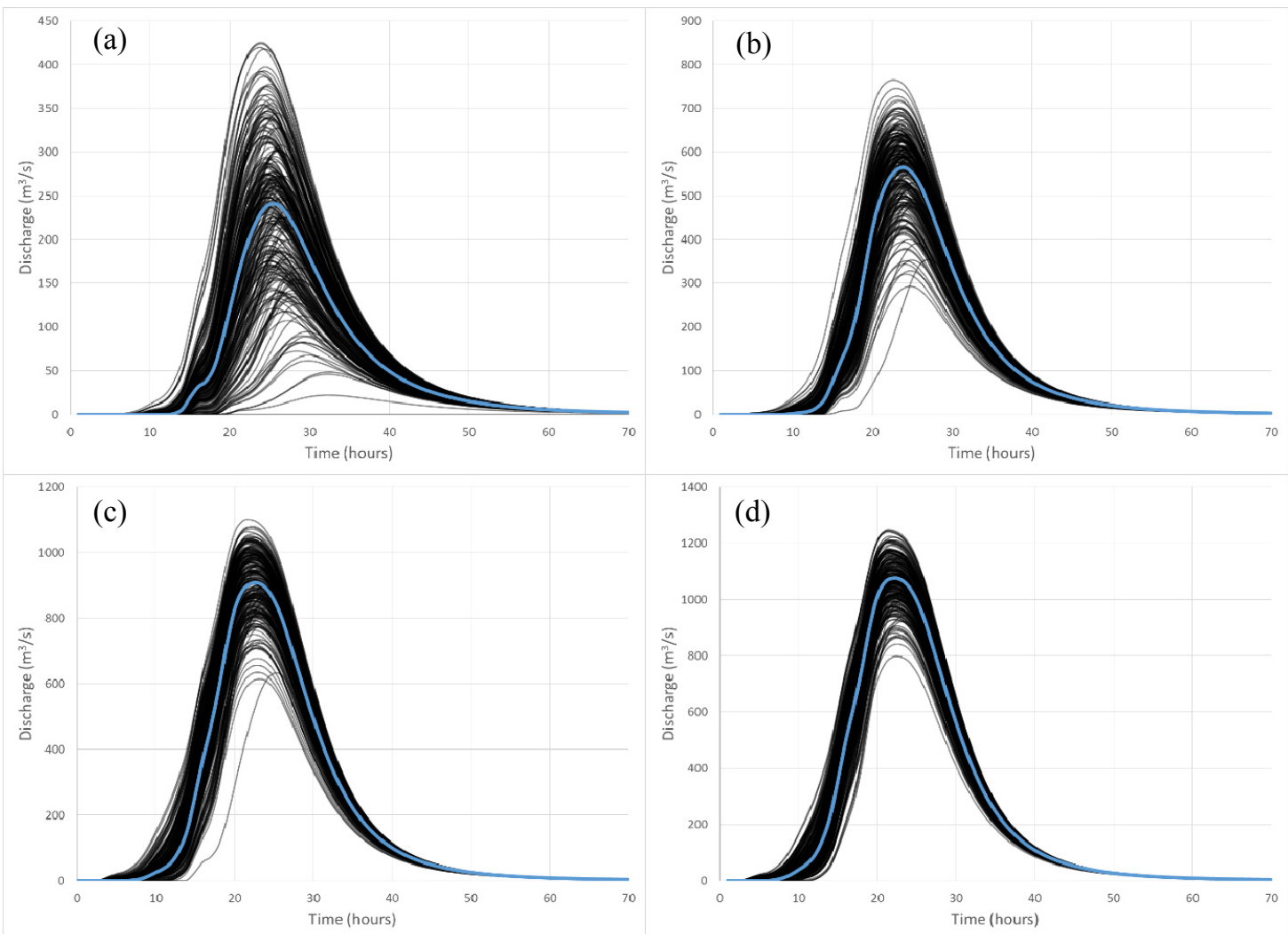

Figure 6: A sample of the flood hydrographs simulated for with 12 hour durations and AEP's of (a) 0.39, (b) 0.10 , (c) $0.02 \&$ (d) 0.01 ; the blue line is the median of all 10,000 generated hydrographs.

Flood inundation modelling should consider all relevant flooding scenarios and their given probabilities, along with a complete examination of the associated uncertainties. These models should produce flood maps with probability-weighted floodplain extents, rather than a single deterministic prediction. With increases in the available computing power, examining the uncertainties associated with design floods, model parameters, topography and model structure is quite feasible and is becoming more widely considered by researchers and practitioners alike. One such study, by Merwade et al. (2008), investigated uncertainties in flood inundation mapping. They found that standard errors in peak flows, ranging from $-36.1 \%$ to $56.5 \%$, caused shifts in the water surface elevation from -0.4 to $1 \mathrm{~m}$ and the extent of floodplain inundation varied in width from $54.3 \mathrm{~m}$ to $90.2 \mathrm{~m}$. In this study, it was shown that the peak flow varies about $\pm 55 \%$ for an AEP of 0.39 . Which, as shown by Merwade et al. (2008) could potentially lead to significant ranges for both the water surface elevation and inundation extents. Research into the impact of these simulated hydrographs (using Monte Carlo simulation) on flood inundation modelling is ongoing. 


\section{CONCLUSIONS}

When the DFFC from the Monte Carlo simulation were compared to the at-site FFA they were found to be reasonable, though the peak flows were consistently overestimated and the flood volumes consistently underestimated. It has been shown that uncertainties in design losses, using the RORB rainfall-runoff model, can make differences of up to about $\pm 55 \%$ for peak flows, $\pm 105 \%$ for flood volumes and $\pm 9 \%$ for time to peak flows. This degree of uncertainty will most likely lead to significant uncertainties in the flood inundation predictions, so should be considered when performing the hydraulic analysis. This is being investigated as part of this research, which will be published in the near future. It should be noted that this study only adopted a limited Monte Carlo framework, which focused on investigating the uncertainties in the losses. In reality all hydrologic variables should be treated stochastically, including the rainfall depth, rainfall temporal and spatial patterns, storm duration and baseflow contribution, however, this is beyond the scope of this paper.

\section{REFERENCES}

Hill, PI, Graszkiewicz, Z, Sih, K \& Rahman, A (2013), Project 6: Loss Models for Catchment Simulation Rural Catchments, Report prepared by Sinclair Knight Merz for the Institution of Engineers.

Ilahee, M. and Imteaz, M.A. (2009) Improved continuing losses estimation using initial loss-continuing loss (IL-CL) model for medium sized rural catchments, American Journal of Engineering and Applied Sciences, 2(4): 796-803.

Ishak, E \& Rahman, A (2006), 'Investigation into Probabilistic Nature of Continuing Loss in Four Catchments in Victoria', in Proceedings of the 30th Hydrology and Water Resources Symposium, Launceston.

Kuczera, G (1999), 'Comprehensive at-site flood frequency analysis using Monte Carlo Bayesian inference', Water Resources Research, 35(5): 1551-1557.

Laurenson, EM, Mein, RG \& Nathan, RJ (2007), 'RORB - Version 6 User Manual', Department of Civil Engineering, Monash University and SKM.

Loveridge, M \& Rahman, A (2012), 'Probabilistic losses for design flood estimation: A case study in New South Wales', in Proceedings of the 34th Hydrology and Water Resources Symposium, Sydney, pp. 9-16.

Loveridge, M, Rahman, A, Hill, P \& Babister, M (2013), 'Investigation into probabilistic losses for design flood estimation: A case study for the Orara River catchment, NSW', Australian Journal of Water Resources, 17(1): 13-24.

Haddad, K \& Rahman, A (2012), 'Regional flood frequency analysis in eastern Australia: Bayesian GLS regression-based methods within fied region and ROI framework - Quantile regression vs. parameter regression technique', Journal of Hydrology, 430-431: 142-161

Mein, RG, Nandakumar, N \& Siriwardena, L (1995), Estimation of Initial Loss from Soil Moisture Indices (Pilot Study), CRC for Catchment Hydrology, Working Document 95/1.

Merwade, V, Olivera, F, Arabi, M \& Edleman, S (2008), 'Uncertainty in flood inundation mapping: Current issues and future directions', Journal of Hydrologic Engineering, 13(7): 608-620

Murphy, R, Graszkiewicz, Z, Hill, PI, Neal, B \& Nathan, R (2011), Project 7: Baseflow for catchment simulation, Report prepared by Sinclair Knight Merz for the Institution of Engineers, Australia.

Nandakumar, N, Mein, RG and Siriwardena, L (1994), Loss Modelling for Flood Estimation - A Review, CRC for Catchment Hydrology, Working Document 94/4.

Rahman, A, Weinmann, PE, Hoang, TMT, Laurenson, EM (2002a), 'Monte Carlo Simulation of flood frequency curves from rainfall', Journal of Hydrology, 256(3-4): 196-210.

Rahman, A, Weinmann, E \& Mein, RG (2002b), 'The Use of Probability-distributed Initial Losses in Design Flood Estimation', Australian Journal of Water Resources, 6(1): 17-29.

Siriwardena, L, Hill, PI \& Mein, RG (1997), Investigation of a Variable Proportional Loss Model for use in Flood Estimation, CRC for Catchment Hydrology, Working Document 97/3.

Tularam, GA \& Ilahee, M (2007), 'Initial Loss Estimates for Tropical Catchments of Australia', Environmental Impact Assessment Review, 27: 493-504.

Walsh, MA (1991), 'Initial Losses for Design Flood Estimation in New South Wales', Masters Dissertation, School of Civil Engineering, UNSW.

Waugh, AS (1990), 'Design Losses in Flood Estimation', Masters Dissertation, UNSW. 